\title{
Programa educacional especializado para capacitação e inclusão no trabalho de pessoas com deficiência intelectual
}

\author{
Annie Gomes Redig a \\ Rosana Glat ${ }^{b}$
}

\section{Resumo}

O artigo discute, no âmbito da Educação Especial, a inclusão profissional de pessoas com deficiência intelectual, a partir da análise da legislação brasileira referente à formação, capacitação e inserção desses sujeitos no trabalho. Apresenta os dados de uma pesquisa que analisou a implementação de um programa especializado, com base no modelo de "trabalho customizado", com quatro jovens alunos de cursos profissionalizantes de uma escola especial que estagiaram na Faculdade de Educação da UERJ. Este conceito baseia-se no processo de preparação tanto do futuro trabalhador quanto na criação e/ou adaptação de postos de trabalho em empresas e outras instituições, adequando a demanda do empregador com as habilidades do sujeito com deficiência. A metodologia utilizada foi a pesquisa-ação, envolvendo avaliação do campo, treinamento e acompanhamento dos sujeitos em suas atividades. Os dados obtidos apontam que a customização do trabalho permitiu um bom desempenho e produção profissional dos treinandos, contribuindo para sua inclusão social no ambiente de trabalho, diminuindo barreiras atitudinais e preconceitos. Abre, portanto, um campo fértil de atuação da Educação Especial.

Palavras-chave: Educação especial. Capacitação e inclusão no trabalho. Deficiência intelectual. Profissionalização de pessoas com deficiência.

\section{Introdução}

O presente artigo tem como foco a inclusão profissional de pessoas com deficiência intelectual. Nessa direção, apresenta algumas das principais peças de legislação brasileira sobre a matéria e discute alternativas programáticas para capacitar e incluir este público no mercado de trabalho. Faz destaque a uma estratégia

\footnotetext{
a Universidade do Estado do Rio de Janeiro (UERJ). Faculdade de Educação. Rio de Janeiro, Rio de Janeiro, Brasil.

b Universidade do Estado do Rio de Janeiro (UERJ). Faculdade de Educação. Rio de Janeiro, Rio de Janeiro, Brasil. 
denominada "trabalho customizado", ilustrando sua utilização em uma recente pesquisa intitulada "Aplicação e análise de um programa customizado para a inclusão de jovens com deficiência intelectual em atividades laborais"1.

\section{Profissionalização da pessoa com deficiência intelectual}

As primeiras iniciativas formais de apoio à profissionalização e inserção laboral de pessoas com deficiências datam do início dos anos 1920, com a preocupação da Organização Internacional do Trabalho - OIT, em garantir empregos para os veteranos mutilados de guerra. A OIT ajudou a estabelecer, em alguns países, a indenização por acidente de trabalho e incentivou, através de diversos programas, a formação profissional, reeducação funcional e colocação no mercado de trabalho de civis e militares com deficiência (GIORDANO, 2000). Esse processo foi reforçado, após a II Guerra Mundial, para atender aos inúmeros ex-combatentes que voltavam do fronte com alguma deficiência. Desde então, diversos países promulgaram peças de legislação estabelecendo cotas para emprego de ex-combatentes, as quais foram, mais recentemente, ampliadas para incluir, também, sujeitos com deficiência, de modo geral (ALMEIDA; CARVALHO-FREITAS; MARQUES, 2009), como será, posteriormente, discutido.

A inserção profissional de pessoas com deficiências pode se dar, segundo Giordano (2000), em quatro modalidades: em função do tipo e grau de deficiência, nível de autonomia do sujeito, e a natureza do posto de trabalho ou função a ser exercida. A primeira, que ele denomina de "trabalho plenamente integrado", é quando o sujeito não precisa de adaptações no ambiente de trabalho. Na segunda, "trabalho integrado", há necessidade de algumas adaptações, que podem ser de caráter temporário ou permanente.

A terceira modalidade abrange as chamadas "oficinas pedagógicas, abrigadas ou protegidas" 2 . De modo geral, constituem-se como programas de habilitação profissional realizados em instituições especializados, onde pessoas com deficiência aprendem atividades laborais, porém, de forma descontextualizada da realidade do mundo do trabalho. Nos casos em que há contratos de produção ou prestação de serviços para terceiros, a instituição assume o papel de intermediária no processo de contratação. A última modalidade é o "trabalho domiciliar", desenvolvido na residência do sujeito. Este tipo de arranjo não é exclusivo de

\footnotetext{
Trata-se da tese de doutorado da Profa . Dra . Annie Gomes Redig com orientação da Profa. Dra . Rosana Glat e teve auxílio de bolsa de doutoramento da Coordenação de Aperfeiçoamento de Pessoal de Nível Superior (Capes).

2 Embora existam diferenças conceituais e/ou programáticas entre esses três tipos de oficinas, neste texto, estamos considerando-as como a mesma modalidade. Para uma discussão mais aprofundada, ver Giordano (2000).
} 
pessoas com deficiência, porém, no caso dessas, frequentemente é intermediado por profissionais especialistas.

No Brasil, a formação profissional para pessoas com deficiência, durante muito tempo, foi restrita ao Instituto Benjamin Constant (para cegos) e ao Instituto Nacional de Educação de Surdos. Somente no final da década de 1950, começaram a ser criados, em instituições especializadas, programas de treinamento vocacional e de profissionalização para indivíduos com deficiência intelectual (SILVA, 2006). As primeiras iniciativas de capacitação ao trabalho de jovens e adultos com deficiência intelectual foram desenvolvidas na Sociedade Pestalozzi do Brasil e Associações de Pais e Amigos dos Excepcionais (APAE), em oficinas. Estas, conforme mencionado, oportunizam ao sujeito a experiência de vivenciar atividades laborais; porém, como não há praticamente nenhum retorno financeiro, a realidade vivenciada é distante da que o aprendiz encontrará em uma futura colocação no mercado de trabalho.

Assim, a oficina acaba caracterizando-se mais como uma atividade ocupacional do que de preparação para ingresso no mercado de trabalho. Como lembra Fogli (2010), na época em que foram criadas, as "oficinas de orientação pré-profissionalizante" para jovens com deficiência intelectual representavam uma proposta inovadora. Porém, com o passar do tempo, esses programas adquiriram um caráter de serviço de reabilitação e não educacional.

Entretanto, no Brasil, a maioria dos projetos de educação profissional para este público ainda é oferecida em oficinas pedagógicas, abrigadas ou similares, em centros de reabilitação, escolas especiais ou núcleos profissionalizantes de instituições especializadas (FOGLI, 2010; MELETTI, 2001). Embora sejam, sem dúvida, espaços importantes de socialização e aprendizagem para pessoas com deficiência intelectual, sobretudo as que apresentam maiores comprometimentos, não cumprem a função de preparação para o ingresso em uma empresa ou outro espaço de trabalho formal.

Como mencionado, os aprendizes desenvolvem atividades laborais sem remuneração, nem sempre cumprindo um horário pré-estabelecido, e as relações com os instrutores e demais profissionais responsáveis são mais de professor e aluno do que empregador e empregado. Ou seja, não há preocupação em capacitar os sujeitos para lidar com a complexidade das regras e relações que permeiam o mundo do trabalho, de forma que possam vir a ser inseridos na primeira ou segunda modalidade de emprego citadas acima. 
Em uma pesquisa recente, Galer (2012) ouviu relatos de 29 adultos com deficiência, que trabalhavam em empregos formais, sobre sua experiência. Nas entrevistas realizadas, entre outras questões, vários participantes comentaram que as atividades laborais que desempenhavam previamente, sem remuneração, por exemplo, o trabalho voluntário, não lhes haviam capacitado para a realidade que encontraram ao ingressar na empresa. Com base nos dados obtidos, o autor concluiu que, em alguns casos, a divulgação desse tipo de experiência pode até prejudicar a imagem da pessoa com deficiência, pois o caráter assistencialista desses programas reforça a representação social estigmatizada sobre o seu suposto fraco desempenho e atitude profissional imatura.

É importante ressaltar, também, que nas oficinas que operam em instituições de ensino especial, geralmente são desenvolvidas atividades de artesanato, culinária, tapeçaria, jardinagem, marcenaria etc. Esses programas são prioritariamente destinados a prover uma ocupação para jovens e adultos que não se encontram mais em processo de escolarização. Não podem ser considerados, portanto, preparação para profissionalização, na medida em que, a não ser em casos específicos, não se adequam às demandas do mercado empregador na comunidade onde estão localizados (FOGLI, 2010).

Um outro tipo de proposta para a profissionalização de pessoas com deficiência, que corresponde ao que Giordano (2000) denomina de "trabalho integrado", é o "emprego apoiado". Esta modalidade consiste no recrutamento de pessoas com deficiências para trabalhar em empresas ou outros espaços na comunidade, com suporte de um treinador ou instrutor laboral (job coach), que atua como mediador na inserção e adaptação do sujeito na empresa (COELHO; ORNELAS, 2010; MATOS, 2013). Parte das atribuições do instrutor laboral, como assinalam Coelho e Ornelas (2010), é negociar previamente com a empresa, visando facilitar a contratação e colocação no mercado de trabalho. Entretanto, este não é um objetivo fácil de ser alcançado, já que a maioria das vagas geralmente disponíveis não são pensadas para pessoas com limitações físicas, sensoriais e /ou intelectuais.

A profissionalização de pessoas com deficiência intelectual é uma questão complexa, que demanda condições diferenciadas para capacitação e inserção em atividades de trabalho, e envolve diversos fatores, entre eles, a qualificação do sujeito para as oportunidades de trabalho oferecidas no mercado. Para Santos, Gomide Neto e Rezende (2012), um programa de preparação para o trabalho implica três fases: 1) fase educativa, aquisição de competências voltadas para atividades de vida diária, habilidades sociais e assumir responsabilidades; 2) treinamento específico de habilidades, o desenvolvimento de aptidões e habilidades baseados 
nos interesses e habilidades do indivíduo; 3) produção e colocação no trabalho, a fase final - sua inserção no mercado de trabalho, com ou sem suporte.

Porém, Cordeiro (2013, p. 29-30) alerta que

[...] a educação profissional não deve ser reduzida ao ensino de habilidade ou técnicas específicas, ou mesmo ao ensino de comportamentos adequados e menos desviantes para as pessoas com deficiências, mas principalmente, deve visar à formação do homem para o mundo do trabalho, com as diversas relações que se travam nele, para que tenha conhecimento de seus direitos e deveres e possa se mobilizar e atuar por mudanças.

Meletti (2001, p. 85) corrobora com essa visão pontuando que "para estar apto a trabalhar no mercado competitivo, o deficiente mental [intelectual] necessita também de aprender habilidades que possam ser generalizadas em outras situações de trabalho que não aquelas nas quais foi treinado". Entretanto, conforme discutido, a maioria dos programas de formação profissional apresenta afastamento e desarticulação com a realidade social da comunidade, e poucos estendem suas ações para o oferecimento de um sistema de suporte nos postos de trabalho. Consequentemente, não há um fluxo regular de encaminhamento desses sujeitos para o mercado de trabalho, reforçando o estigma de incapacidade. Para transformar este cenário, é fundamental que se criem programas de orientação e formação profissional que visem ampliar conhecimentos e habilidades dos aprendizes para o trabalho, de forma a proporcionar experiência mais articulada com a realidade social (CORDEIRO; OLIVEIRA, 2011).

No Brasil, há várias peças de legislação que dão respaldo a este tipo de proposta. O Programa de Qualificação de Trabalhadores na área de Pessoas Portadoras de Deficiência, criado em 1996, é um exemplo de ação política para oferecer ao jovem e adulto com deficiência uma educação profissional, através de parcerias com empresas e sindicatos (FOGLI, 2010). A Resolução n ${ }^{\circ} 2$, de 2001, do Conselho Nacional de Educação (BRASIL, 2001), por sua vez, preconiza que a rede de ensino profissional oportunize o acesso e permanência de alunos com deficiência na escola, oferecendo as adequações necessárias.

Mais recentemente, a Lei $\mathrm{n}^{\circ}$ 12.513, de 26 de outubro de 2011 (BRASIL, 2011), defende a inclusão deste público nas ações de educação profissional e tecnológica desenvolvidas pelo Programa Nacional de Acesso ao Ensino Técnico e Emprego - Pronatec, "observadas as condições de acessibilidade e participação 
plena do indivíduo". Incentiva, também, a expansão de ofertas de vagas para alunos com necessidades especiais, nas instituições públicas federais e estaduais de Educação. No entanto, os programas de auxílio financeiro (bolsas e estágios remunerados), só contemplam os estudantes com deficiência inscritos em cursos técnicos de nível médio e superior. Logo, há um grande quantitativo de jovens e adultos com deficiência que são excluídos da oportunidade de participação nos cursos profissionais (tanto nos de formação inicial e continuada, quanto técnicos e tecnólogos), visto que esses exigem certificação de escolaridade mínima. Isto é, sobretudo, verdadeiro para pessoas com deficiência intelectual, que raramente preenchem este requisito acadêmico (FOGLI, 2010).

Em 1990, foi promulgada a Lei $\mathrm{n}^{\circ} 8.112$ (BRASIL, 1990), que obriga a reserva de até $20 \%$ do percentual das vagas em concursos públicos para pessoas com deficiência. Esta foi seguida pela Lei $n^{\circ}$ 8.213/91 (BRASIL, 1991), conhecida como "Lei de Cotas", que estipula empresas com mais de 100 funcionários a reservar vagas para essa população ${ }^{3}$. Sabe-se, porém, que estas determinações, na prática, nem sempre são preenchidas, visto que, para ser contratado, naturalmente, o indivíduo, independente de ter ou não uma deficiência, precisa estar qualificado para exercer as atribuições do cargo.

Um significativo avanço foi a recentemente aprovada Lei $\mathrm{n}^{\circ} 13.146$ (BRASIL, 2015), que preconiza que "a colocação competitiva da pessoa com deficiência pode ocorrer por meio de trabalho com apoio", observadas algumas diretrizes. Entre elas, na seção III, Art. 37, a "provisão de suportes individualizados que atendam a necessidades específicas da pessoa com deficiência, inclusive a disponibilização de recursos de tecnologia assistiva, de agente facilitador e de apoio no ambiente de trabalho".

Historicamente, pessoas com deficiência intelectual são marginalizadas e excluídas de oportunidades do convívio em sociedade. Deliberadamente ou não, elas têm sido privadas "de uma série de bens culturais e intelectuais, prejudicando-as no seu processo de inserção social e trabalhista" (ARAUJO; SCHMIDT, 2006, p.242). Neste sentido, não basta a criação de leis que estimulem a participação deste público em cursos profissionalizantes, ou mesmo que obriguem sua contratação no serviço público e em empresas privadas. Uma efetiva inclusão profissional só será possível com a flexibilização e adaptação das leis trabalhistas, bem como das condições de trabalho: redução da carga horária diária e /ou semanal, oferecimento de apoio para o trabalhador, utilização de tecnologia assistiva etc.

É estabelecido na Lei de Cotas (BRASIL, 1991) que deve ser reservado $2 \%$ das vagas para pessoas com deficiência em empresas que possuem entre 100 e 200 funcionários; 3\% das vagas para 201 a 500; 4\% para 501 a 1.000 e $5 \%$ das vagas para empresas com mais de 1.000 funcionários. 


\section{Transição da vida escolar para o mundo do trabalho}

Embora a proposta de Educação Inclusiva seja, hoje em dia, amplamente disseminada, inclusive pela mídia, é importante lembrar que as políticas de inclusão social de pessoas com deficiência não se restringem ao espaço escolar. Independentemente das condições de escolarização, alunos com deficiência, assim como os demais, precisam se preparar para sua futura inserção no mundo do trabalho.

Entretanto, como discutido, embora a legislação brasileira seja propiciadora da inclusão, ela não garante, por si só, esse acolhimento. São necessárias ações efetivas que contribuam para a superação dos preconceitos e a transformação das relações tradicionalmente estabelecidas entre pessoas com deficiências e os ditos "normais". Acreditamos que essas barreiras serão mais facilmente vencidas se jovens com deficiência forem expostos a um processo programado de transição da escola para a vida adulta e o mundo de trabalho, que lhes instrumentalize a lidar mais adequadamente com a nova etapa (GILLIES, 2012; REDIG, 2014).

O término da escolarização e ingresso na vida adulta, por assim dizer, é um período marcante para qualquer estudante. Representa, para alguns, uma série de oportunidades de crescimento e desenvolvimento social, mas para outros pode se constituir de um acúmulo de experiências frustrantes. Isso acontece, sobretudo, nos casos em que a transição não é bem estruturada e o aluno não recebe orientação e/ou suporte adequados. Para que jovens com deficiência intelectual tenham um bom desempenho profissional, conforme apontam Comin e Lincoln (2012), é fundamental que sua formação continue após o período escolar.

Nos Estados Unidos, na maioria dos Estados, a idade máxima para permanência no sistema escolar é 21 anos, mesmo para alunos com necessidades especiais. Assim, em muitas escolas, há programas estruturados para atender esses alunos no seu processo de transição para o mundo do trabalho. Estes são realizados por professores especialistas da própria escola e/ou em parcerias com ONGs, através de estágios e empregos temporários. Para tal, é traçado um plano de transição, que faz parte do currículo escolar do aluno, tendo início quando o adolescente com deficiência completa 16 anos de idade 4 . Este tipo de ação é resultante de uma emenda da Lei Educacional para Indivíduos com Deficiência

MARTIN-LUECKING, D. Plano de transição e programa de ensino individualizado - PEl. Palestra ministrada na Universidade do Estado do Rio de Janeiro, 2012. 
(The Individuals with Disabilities Education Act-IDEA ${ }^{5}$ ), a qual se baseia em seis princípios: "1) rejeição zero ${ }^{6} ; 2$ ) avaliação não discriminatória; 3) educação gratuita e apropriada; 4) ambiente menos restritivo possível; 5) emolumentos judiciais; 6) participação aluno / família" (PETERSON, 2006, p.4).

Indubitavelmente, se, durante o período escolar, um jovem (e isso não se aplica apenas aos com deficiência) estiver inserido em um ambiente em que tenha voz ativa, poder de decisão e no qual sejam proporcionadas atividades adequadas para seu nível de desenvolvimento, certamente ganhará confiança em si mesmo e estará mais habituado e seguro para vivenciar as mesmas experiências que os demais.

Em nosso país, a Educação Especial é disponibilizada "ao longo de toda a vida" (BRASIL, 2011), ou seja, não há prazo de terminalidade do percurso de seu público-alvo. Logo, é facultado que adultos com deficiência permaneçam na instituição, ou em classes especiais sem previsão de jubilação, o que dificulta o seu ingresso no mundo do trabalho e na vida adulta, de modo geral. É importante ressaltar que a inclusão de jovens com deficiência em atividades laborais não significa a interrupção do seu processo educativo, até porque, no trabalho, estamos em constante aprendizado de habilidades sociais, comportamentais etc. Porém, esse aprendizado deverá, como para os demais, acontecer em outros espaços além da escola, até porque, na sociedade contemporânea, todo mundo precisa de formação continuada.

Trabalhar é importante, não apenas por razões econômicas, mas porque faz o indivíduo se sentir útil, ocupando um espaço no lócus social. Porém, conforme discutido, pessoas com deficiência, principalmente intelectual, enfrentam grandes dificuldades para se inserir no mercado de trabalho, tanto por razões objetivas (pouca escolarização e/ou qualificação profissional), quanto pela representação social estigmatizada a respeito de sua capacidade produtiva.

As probabilidades de inserção no mercado de trabalho serão maiores se o jovem tiver participado de um programa estruturado, envolvendo, sobretudo, o desenvolvimento de habilidades sociais, e se o suporte especializado for ampliado para o período pós-escola. Certamente, tais ações não devem ser dirigidas apenas aos estudantes com deficiências, pois, "os programas de transição da escola para o trabalho beneficiam toda a juventude independentemente da deficiência e tais

\footnotetext{
Segundo Nunes Sobrinho e Lucena (2011), 50 Estados americanos cumprem os requisitos dessa lei. Para uma discussão aprofundada do documento citado, ver Oliveira, Goulart Júnior e Fernandes (2009).

6 Cezar (2012, p. 42) explica que "a rejeição zero significa a não possibilidade de recusar uma pessoa para qualquer finalidade, seja ela, empregatícia, educacional, terapêutica etc. Por esse princípio, ninguém pode ser rejeitado pelo fato de possuir uma deficiência, mesmo que esta seja muito severa".
} 
experiências oferecem aos alunos um sentido mais rico e mais significativo da educação" (ABREU-ELLIS; ELLIS, 2011, p. 84).

Tomando como exemplo a realidade norte-americana, Luecking (2009) lembra que há diferentes formas de se oferecer a estudantes do Ensino Fundamental e Médio oportunidades de inserção ao mundo do trabalho como aspectos integrantes de sua formação educacional, na forma de estágios ou atividades extracurriculares. Em parte, isso já acontece no Brasil, nos cursos técnicos, onde o aluno frequenta as aulas em um horário e realiza estágios para a sua formação profissional no contra turno. Essa proposta também é desenvolvida em escolas especiais no formato de cursos de Formação Inicial e Continuada - FIC (MASCARO, 2012).

Independentemente de frequentarem escolas comuns ou especiais, autores como Luecking (2009) são categóricos quanto à importância da participação de alunos com deficiência em programas de transição para o trabalho, por meio de ações, tais como visitas e estágios de curta duração em empresas ou instituições que despertem o interesse para o trabalho e estimulem os sujeitos a perceber suas habilidades e vocações. Além disso, programas de transição ajudam alunos com deficiência a obter as experiências laborais que tanto as empresas exigem.

Esse tipo de proposta representa uma excelente oportunidade para aprendizagem, pois, quanto mais o jovem for exposto a diferentes experiências no mundo do trabalho, melhor ele poderá fazer sua opção profissional, bem como identificar os suportes que precisará. Durante as visitas, o professor pode aproveitar para se informar sobre as características que a empresa valoriza nos seus funcionários. Posteriormente, ele discutiria esses aspectos com seus estudantes, explorando que tipo de atividades laborais eles gostariam de desempenhar se fossem contratados por aquela empresa, e que atributos precisariam desenvolver para conseguir essa colocação.

Em uma pesquisa na qual foram entrevistados jovens e adultos com deficiência intelectual que haviam passado por várias empresas, a insatisfação dos sujeitos com trabalho que deveriam desempenhar foi apontada como um dos principais fatores de instabilidade no emprego (CEZAR, 2012). Justamente por essa razão é importante que programas de profissionalização e inclusão em atividades de trabalho para pessoas com deficiência (aliás, para qualquer pessoa) tenham como um dos objetivos básicos identificar que tipo de atividade elas se sentiriam bem em realizar e em que ambientes de trabalho elas teriam maiores chances de serem bem-sucedidas. 


\section{Inclusão de jovens com deficiência intelectual em atividades profissionais por meio da customização do trabalho}

Embora em nosso país a legislação garanta, através do sistema de cotas, a contratação de pessoas com deficiências, a política de inclusão laboral não será alcançada apenas com base neste tipo de dispositivo. Até porque, conforme tem sido observado, algumas empresas contratam pessoas com deficiências apenas para evitar sanções; não exigem sua frequência e /ou as deixam subutilizadas, sem uma função ou tarefa relevante para desempenhar. Ou seja, formalmente estão empregadas, mas, na prática, não estão trabalhando.

Este tipo de situação corresponde ao que Sawaia (2004, p. 35) denomina de "violência moral" que, "no plano social sustenta todas as formas de inclusão perversa, o que significa a inserção social pela perda da dignidade, pelo preconceito e culpabilização por sua própria condição social”. Em outras palavras, como não se acredita no potencial de produtividade de pessoas com deficiência, o foco é, geralmente, colocado nas limitações do sujeito e não se reconhece as barreiras existentes no ambiente de trabalho bem como a dificuldade das demais pessoas em lidar com ele.

Para que a inclusão profissional, de fato, seja assegurada, são necessárias estratégias que capacitem esses indivíduos para serem absorvidos pelo mercado de trabalho, ter um bom desempenho e manter seus empregos. Com esse objetivo, foi desenvolvido, nos Estados Unidos, o conceito de "trabalho ${ }^{7}$ customizado". Esta proposta parte do pressuposto de que pessoas com deficiência, mesmo as que apresentam grande comprometimento, são capazes de produzir e contribuir com a empresa ou instituição se houver adaptações e/ou suportes adequados em seu local de trabalho. Esta noção aparece no já citado The Americans with Disabilities Act (ADA), e tem como princípio básico enfatizar as qualidades e aptidões de cada sujeito, adaptando a atividade a ser desempenhada de acordo com sua habilidade.

Este aspecto é fundamental, porque um empregador não pode esperar que um funcionário com deficiência (aliás, qualquer funcionário) cumpra tarefas para as quais não tenha, no momento, habilidade para exercer. No entanto, esse sujeito pode ser bem aproveitado a partir da adaptação ou criação de um posto

O termo original em inglês é customized job, que significa, literalmente, "emprego customizado". Entretanto, preferimos utilizar a expressão "trabalho customizado", na medida em que, como será demonstrado, a utilização desta metodologia não se restringe a situações de emprego formal. 
de trabalho que, originalmente, não existia, mas que aumentaria a produtividade geral do setor, por exemplo, liberando outros funcionários para atividades mais qualificadas (REDIG; MASCARO; CARLOU, 2013).

De acordo com Luecking (2011), o trabalho customizado é o resultado da reestruturação ou criação de atividades em um posto de trabalho, visando à inclusão de pessoas com deficiência que, de outra forma, não poderiam ser contratadas. Este processo exige, contudo, a avaliação das habilidades e potencial de aprendizagem do futuro trabalhador e as possibilidades de adequação do ambiente de trabalho. Logo, é fundamental a atuação de um profissional especializado, denominado instrutor laboral, para montar o programa, bem como supervisionar e acompanhar inicialmente o novo funcionário na realização das tarefas.

Becerra et al. (2008) descrevendo um programa semelhante para pessoas com deficiência intelectual desenvolvido na Espanha, esclarecem que esse instrutor, também conhecido como preparador laboral/especialista en empleo, é um profissional que tem como função fazer a intermediação entre o trabalhador e a empresa, bem como desenvolver ou encontrar a melhor adaptação possível. O suporte deve ser exercido de forma decrescente (ou seja, aos poucos, sua intervenção é reduzida) para que o sujeito com deficiência desenvolva as tarefas, fazendo com que ele estabeleça as metas, planeje suas ações e avalie os resultados de forma autônoma.

Para Griffin, Hammis e Geary (2011), a customização do trabalho representa a individualização da relação de trabalho entre empregador e empregado, na medida em que combina as habilidades do trabalhador às necessidades da empresa. Um programa de trabalho customizado envolve três etapas básicas. A primeira é a avaliação das aptidões, dificuldades e interesses da pessoa com deficiência em busca de emprego, de forma que possa ser oportunizado um posto de trabalho no qual ela terá uma maior probabilidade de ser bem-sucedida. Esta avaliação geralmente é feita por meio de entrevistas e/ou a utilização de um inventário de habilidades e competências denominado Perfil Pessoal Positivo - PPP (GRIFFIN et al., 2011; LUECKING, 2009; 2011; 2012; REDIG, 2014).

A segunda etapa (que pode anteceder ou ser concomitante à primeira) consiste em buscar, na comunidade, possibilidades de emprego que atendam ao perfil do sujeito e, na medida do possível, às suas expectativas. Esta fase envolve, entre outras ações, visitas a empresas e instituições da comunidade para acessar possibilidades de emprego, não só levantando as vagas já abertas, mas também a demanda da empresa, ou seja, qual a necessidade da instituição. Conforme mencionado, muitas vezes um posto de trabalho já existente pode ser desmembrado 
em diferentes atividades laborais, ou vir a ser criado um novo posto de trabalho que possa ser preenchido pela pessoa com deficiência.

Como, porém, o objetivo não é apenas que o sujeito consiga ser contratado, mas que tenha bom desempenho e permaneça no emprego, a terceira fase envolve elaboração e implementação de um sistema de suporte atendendo às necessidades especiais do empregado. Às vezes, é necessário um acompanhamento direto, por algum tempo, do instrutor laboral, não só para dar suporte à realização das tarefas, mas também para a adaptação e integração da pessoa no ambiente de trabalho, incluindo facilitação na negociação dos benefícios, como salário, plano de saúde, horário reduzido (se necessário) etc. Esta proposta potencializa a inclusão laboral de indivíduos com deficiência, de acordo com suas aptidões, minimizando a competição perversa do mercado de trabalho. Por outro lado, evita o viés assistencialista, na medida em que o sujeito, de fato, está exercendo uma função produtiva.

Antes de prosseguir, é importante ressaltar que "emprego apoiado", citado anteriormente, e "trabalho customizado", embora tenham o mesmo objetivo e algumas das mesmas estratégias, como o suporte de um instrutor laboral ou outro profissional especializado, são modalidades distintas de inserção da pessoa com deficiência no mercado de trabalho. No emprego apoiado os sujeitos são contratados para assumir uma função já existente na empresa. $\mathrm{O}$ trabalho customizado, por sua vez, envolve a criação de uma nova função ou adaptação de um posto de trabalho, combinando o interesse e habilidades do empregado com as necessidades do empregador.

Pode-se dizer que, neste caso, a atividade não é customizada apenas para a pessoa com deficiência, mas também para a empresa. O grande desafio que se coloca é encontrar um emprego no qual o sujeito possa ter sucesso, o que nem sempre se resume a enquadrá-lo a uma vaga já existente. Porém, independente do modelo utilizado, qualquer estratégia que incentive a empregabilidade da pessoa com deficiência é válida, pois o importante é que ela trabalhe!

Para Luecking (2012) e Martin-Luecking (2012) ${ }^{4}$, o elemento que dá consistência ao processo de customização do trabalho é a elaboração do PPP mencionado anteriormente, pois este instrumento permite destacar as qualidades positivas do indivíduo, ao invés de suas limitações, ou seja, sua deficiência. Além do inventário, propriamente dito, o PPP é traçado com base em entrevistas com o sujeito, professores e familiares sobre atividades acadêmicas, de lazer e cotidianas, por exemplo, atividades de vida diária. É muito importante que o próprio indivíduo com deficiência participe ativamente da elaboração do seu perfil, e que sejam ouvidas pessoas significativas 
em sua vida, como familiares, amigos, professores e demais profissionais que o atendam. Também podem ser colhidas informações complementares em documentos, como registros escolares e médicos. Embora seja um procedimento complexo envolvendo a participação de diversos atores, não há dúvida de que um PPP bem traçado facilite e otimize não só o processo de empregabilidade, como pode também apontar estratégias para inclusão social de modo geral.

Como ilustração, apresentamos a seguir uma pesquisa envolvendo a aplicação de um programa customizado para a inclusão de jovens com deficiência intelectual, em atividades laborais em uma Instituição de Ensino Superior.

\section{Implementação e avaliação de um programa de customização do trabalho}

Nesta pesquisa, a proposta de customização do trabalho foi utilizada para o treinamento em serviço de alunos com deficiência intelectual integrantes de um curso profissionalizante de uma escola especializada da Fundação de Apoio à Escola Técnica do Estado do Rio de Janeiro - Faetec. Os sujeitos, aqui denominados como treinandos, realizaram o módulo prático do curso, na forma de estágio ${ }^{8}$, na Faculdade de Educação da UERJ.

O estudo foi desenvolvido com base na pesquisa-ação, um método de investigação científica, concebido e realizado em estreita associação com uma ação voltada para a resolução de uma situação-problema (JESUS, 2010). Trata-se, portanto, de uma pesquisa aplicada, que tem como característica principal o envolvimento direto do pesquisador (MARTINS, 2010) e a participação ativa dos sujeitos pertencentes ao campo onde o projeto é desenvolvido.

Uma "característica básica da pesquisa-ação é a sua flexibilidade, que possibilita condições para um diálogo permanente, agregando contribuições trazidas por cada um dos sujeitos, permitindo a elaboração coletiva de soluções para os possíveis problemas enfrentados" (GLAT; PLETSCH 2012, p. 109). A pesquisa-ação é um procedimento muito profícuo na área das Ciências Humanas e Sociais na medida em que não conduz apenas à produção de conhecimento, mas traz repercussões práticas para os participantes do estudo. Não se trata, porém, de uma mera "intervenção" ou "prestação de serviço", pois, como lembra Thiollent (2011), a ação dos atores envolvidos na situação-problema tem um caráter investigativo, pois é sistematicamente elaborada, implementada e avaliada, de forma crítica e participativa.

Como demais estagiários integrantes do convênio entre a Faetec e UERJ, os participantes recebiam uma bolsa auxílio durante o treinamento. 
A pesquisa formal ${ }^{9}$ teve duração de seis meses, com uma média de duas sessões semanais de aproximadamente duas horas, totalizando 35 encontros. Participaram, como sujeitos primários, quatro jovens com deficiência intelectual, alunos de uma escola especial da rede pública do Estado do Rio de Janeiro, onde frequentavam o curso de Formação Inicial e Continuada (FIC) em auxiliar em serviços gerais (limpeza) e contínuo-reprografia (auxiliar administrativo). O Quadro 1 apresenta os dados dos sujeitos.

Seguindo o modelo de trabalho customizado, a capacitação, acompanhamento e avaliação do desempenho dos treinandos, na realização das tarefas, foram realizados pelas instrutoras laborais. No escopo do estudo, esse papel foi desempenhado pela pesquisadora, duas estudantes do último período do Curso de Pedagogia e a secretária do Gabinete da Direção da Faculdade, que fazia o Curso de Especialização em Educação Especial, conforme mostra o Quadro 2.

Para a coleta de dados, foram utilizados registros de diário de campo ${ }^{10}$ feitos pela pesquisadora e as demais instrutoras laborais, após cada sessão.

Quadro 1. Quadro representativo com os dados dos alunos indicados pelos professores.

\begin{tabular}{|l|c|c|c|}
\hline Treinandos* & Curso & $\begin{array}{c}\text { Idade } \\
\text { (anos) }\end{array}$ & $\begin{array}{c}\text { Tempo na } \\
\text { Instituição (anos) }\end{array}$ \\
\hline Eduardo & Auxiliar de Serviços Gerais & 27 & 14 \\
\hline Lucas & Auxiliar de Contínuo-Reprografia & 25 & 13 \\
\hline Tatiana & Auxiliar de Serviços Gerais & 22 & 15 \\
\hline Pedro & Auxiliar de Contínuo-Reprografia & 25 & 15 \\
\hline
\end{tabular}

*Os nomes são fictícios.

Fonte: Dados da pesquisa, 2015.

Quadro 2. Quadro representativo dos dados das instrutoras laborais.

\begin{tabular}{|l|c|c|}
\hline Instrutor Laboral & Função & $\begin{array}{c}\text { Aluno } \\
\text { Acompanhado }\end{array}$ \\
\hline Instrutora Laboral 1 & $\begin{array}{c}\text { Secretária do Gabinete da Direção da Faculdade de } \\
\text { Educação, aluna do curso de especialização em EE }\end{array}$ & Pedro \\
\hline Instrutora Laboral 2 & Aluna do curso de Pedagogia & Lucas \\
\hline Instrutora Laboral 3 & Aluna do curso de Pedagogia & Eduardo e Tatiana \\
\hline Instrutora Laboral 4 & Pesquisadora & Eduardo e Tatiana \\
\hline
\end{tabular}

Fonte: Dados da pesquisa, 2015.

\footnotetext{
9 Após o término do estudo, o projeto teve continuidade, inclusive, com adesão de novos treinandos.

${ }^{10}$ Os registros em diário de campo são anotações que consistem na descrição das atividades de pesquisa, podendo fazer relação teórica aliada à interpretação da situação. É fundamental a descrição exaustiva das observações, na medida em que, desse relato, serão extraídos os dados a serem analisados.
} 
Para avaliar o desempenho dos treinandos nas tarefas por eles desenvolvidas, foi elaborada uma tabela (adaptada de WALTER, 2006), na qual se marcava o nível de suporte ${ }^{11}$ que o sujeito necessitava em cada sessão para realizar as diferentes atividades. Esse instrumento teve como objetivo avaliar o grau de autonomia no trabalho que os sujeitos iam adquirindo durante o processo. A análise dos dados ocorreu de forma contínua no decorrer da pesquisa, com base nos registros do diário de campo e na tabela de tarefas.

Ainda de acordo com os procedimentos básicos da customização do trabalho, as atividades que os treinandos desempenhariam foram determinadas pelas necessidades da Faculdade de Educação, levando-se em consideração o seu PPP. As demandas da Faculdade foram identificadas com base em entrevistas semiestruturadas com a Diretora, a Vice-diretora e três coordenadores de setores. A construção do PPP dos treinandos foi feita a partir de entrevistas semiestruturadas com eles e com seus professores na escola especial.

Os treinandos do Curso de Serviços Gerais, Eduardo e Tatiana, trabalharam juntos na limpeza da Faculdade, recolhendo lixo, regando as plantas, arrumando as salas de aula, apagando os registros deixados no quadro-negro, entre outras tarefas. Já Pedro e Lucas, do Curso de Contínuo-reprografia, se dividiram em dois setores. Pedro ficou lotado no gabinete da Direção, guardando documentos, preparando a mesa de lanche, fazendo cópias etc. Lucas, o único que era alfabetizado, trabalhou na secretaria de Educação a Distância (EAD) e, em seguida, foi transferido para a secretaria do Programa do Pós-Graduação em Educação (ProPEd), onde ficou responsável por organizar, em ordem alfabética, as pastas com documentação dos alunos.

Para a realização das atividades customizadas, eles tiveram o apoio presencial dos instrutores laborais. Com base nos registros do diário de campo e da tabela de suporte, foi possível perceber a evolução dos sujeitos no desempenho de suas funções.

Pelo fato de eles estarem matriculados em curso de FIC já em fase de estágio, não houve necessidade de uma capacitação prévia de tarefas corriqueiras como limpar, regar plantas, varrer o chão etc. Entretanto, algumas atividades novas para eles, por exemplo, preparar café na cafeteira, demandaram treinamento mais sistemático, por meio de demonstração e acompanhamento dos instrutores laborais.

${ }^{11}$ Os níveis de suporte variavam de 0 a 4, a saber: 0- não realiza a atividade, 1- realiza com suporte físico, 2- realiza com suporte verbal, 3- com a presença do instrutor laboral, mas sem ajuda física ou verbal e 4- com autonomia, sem supervisão. 
É interessante observar que, além das atividades que haviam sido previamente customizadas, novas atribuições, no decorrer da pesquisa, puderam ser incorporadas à sua rotina, como limpar as salas de pesquisa de alguns professores, limpar a geladeira, fazer café, na medida em que os treinandos adquiriam maior confiança na realização das suas tarefas e em sua integração ao ambiente de trabalho, de modo geral.

Algumas atividades eles aprenderam rapidamente, apenas, inicialmente, com instrução verbal (os instrutores falavam o que deveria ser feito ou davam dicas), ou modelo visual (os instrutores faziam as tarefas junto, e os treinandos copiavam), enquanto para outras houve necessidade de adaptações e/ou utilização de recursos específicos. Um instrumento desenvolvido que se mostrou bastante eficaz foi uma ficha, entregue a cada sujeito, com imagens das tarefas que eles deveriam executar, na qual, ao fim de cada dia, marcavam o que haviam cumprido, aprendendo, assim, a se auto monitorar e avaliar seu próprio desempenho.

Sem pretender nos estender em uma descrição detalhada das atividades desenvolvidas pelos treinandos durante a pesquisa, apresentamos, a seguir o caso de Lucas, o único dos sujeitos que era alfabetizado. Lucas era muito tímido, quase não falava, mas tentava ao máximo se concentrar para executar seu serviço com perfeição.

A sua primeira tarefa na secretaria da Educação a Distância foi rasgar documentos anteriores ao ano de 2010. Esse é um típico exemplo de função customizada, visto que, conforme colocado pela Coordenadora, há muito tempo que essa tarefa precisava ser feita para liberar espaço nos armários, porém, os funcionários da Faculdade tinham outras prioridades. Lucas foi então designado para desempenhar essa função. A secretária da EAD separava os documentos que podiam ser inutilizados e o treinando se encarregava de rasgar e jogar fora, o que desincumbiu com facilidade e rapidez, logo ficando subutilizado, já que não havia outras demandas, no momento, neste setor.

Entretanto, quando as secretárias do Programa de Pós-graduação tomaram conhecimento do projeto, solicitaram um estagiário para auxiliar na organização, em ordem alfabética, das fichas dos alunos no arquivo, tarefa que também estava pendente há muito tempo. Como Lucas era alfabetizado, foi imediatamente transferido, onde trabalhou com bastante eficiência até o término do seu estágio.

Para a realização dessa tarefa, foi utilizado como suporte um alfabeto numerado (Figura 1), para que Lucas pudesse visualizar a ordem das letras. Para facilitar, ele escrevia em um papel alguns nomes que estavam nas fichas dos alunos do Programa (Figura 2) e após isso, Lucas conseguia comparar as letras até alcançar 


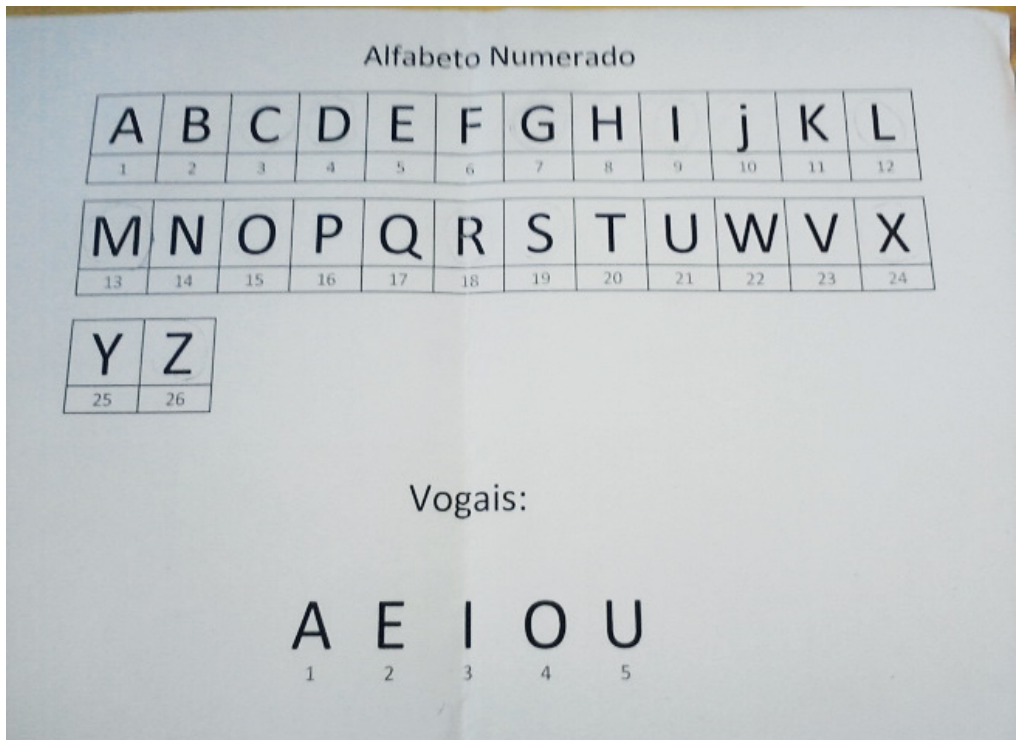

Fonte: Elaboração própria.

Figura 1. Alfabeto numerado, elaborado pela instrutora laboral 2.



Fonte: elaboração própria.

Figura 2. Lucas comparando os nomes dos alunos. 
a diferente para, assim, com a ajuda do alfabeto numerado, perceber qual a ordem alfabética dos nomes.

Como já mencionado, a customização do trabalho envolve a criação de tarefas novas que possam ser realizadas pelo sujeito com deficiência aprimorando a produtividade geral do setor, como foi o caso de Lucas nas duas secretarias em que trabalhou. Também implica na adaptação de atividades já existentes para que estes indivíduos possam realizar com competência e autonomia, como foi feito na função de limpeza da Faculdade realizada por outros treinandos.

O desenvolvimento dos treinandos, tanto em termos de eficiência, quanto de autonomia e integração social no ambiente de trabalho, de modo geral, foi confirmado por observações de campo, análise da tabela de suportes, bem como comentários informais e entrevistas com os próprios sujeitos, funcionários (docentes e técnico-administrativos) da Faculdade de Educação que com eles conviveram. Entrevistas com seus familiares e professores da escola especial confirmaram a relevância da experiência para o seu processo de amadurecimento e transição para a vida adulta. Os dados obtidos vêm de encontro com as recomendações de Luecking $(2010 ; 2013)$ para inclusão, no currículo escolar de experiências laborais, sobretudo atividades remuneradas em ambientes que correspondam à realidade do mundo do trabalho.

Pelos dados obtidos neste estudo, podemos afirmar que o modelo de trabalho customizado, baseado na análise da demanda do empregador e o perfil pessoal positivo do empregado, é uma profícua alternativa para a capacitação e inclusão no trabalho de pessoas com deficiência intelectual. Os participantes alcançaram autonomia realizando suas tarefas com eficiência, ampliando sua esfera de atuação e desenvolvendo relações sociais com os colegas e outros integrantes da comunidade da Faculdade de Educação.

Luecking (2009) refere-se ao trabalho customizado como uma win-win situation - "situação em que todos ganham". Ou seja, o empregador ganha com a produção do funcionário (e, no caso do Brasil, cumpre as cotas) e esse ganha os benefícios do emprego. No contexto deste estudo, os treinandos ganharam experiência ${ }^{12}$ e remuneração (pela bolsa) e a Faculdade de Educação teve um melhor serviço de limpeza e de secretaria, atendendo suas demandas iniciais.

\footnotetext{
${ }^{12}$ No final do treinamento, os treinandos receberam um certificado de conclusão do estágio e uma carta de recomendação, assinada pela Diretora da Faculdade de Educação.
} 


\section{Considerações finais}

Conforme discutido, apesar do incentivo da legislação e a crescente conscientização da opinião pública de que pessoas com deficiência têm direito e condições de trabalhar, ainda são muitos os desafios a serem enfrentados para garantir uma inclusão profissional mais equânime para essa população. Empregadores frequentemente apontam dificuldade em encontrar uma pessoa com deficiência que esteja preparada para atender aos requisitos dos postos de trabalho disponíveis. Além disso, a maior parte alega não ter recursos humanos especializados para capacitar funcionários com deficiência recém-admitidos.

A contratação de pessoas com deficiência com base em programas de customização do trabalho oferece uma alternativa viável para superação destas barreiras. Primeiro, pois adequa as demandas da empresa ao perfil do candidato ao emprego, através da adaptação de funções e/ou criação de novos postos de trabalho, de forma que funcionário com deficiência, de fato, está beneficiando a empresa com a sua mão de obra. Em outras palavras, como lembra Cezar (2012), a responsabilidade social da empresa de contratar e manter funcionários com deficiência não prejudica sua lucratividade, desde que este funcionário seja produtivo. Este modelo é profícuo, ainda, porque oferece capacitação do funcionário com deficiência no próprio local de trabalho, com suporte, se necessário, de um instrutor, o que, conforme constatado por diversas pesquisas facilita $o$ aprendizado das atividades e a adaptação no ambiente institucional (CEZAR, 2012; CORDEIRO; OLIVEIRA, 2011; LUECKING, 2009).

Omote (2008) lembra que o ambiente escolar inclusivo não obriga a pessoa com deficiência a cumprir todas as atividades em conjunto. Podemos transferir esta lógica para o mercado de trabalho, convergindo com o conceito de customização, o qual, justamente, consiste em desenvolver atividades, adaptadas, compatíveis com as habilidades do sujeito e considerando o suporte do meio. Nas palavras de Omote (2012, p. 51) "ainda que possa parecer paradoxal, a construção de uma sociedade inclusiva requer a construção de serviços especiais, e não a sua dispensa sob a suposição de que eles só segregam". Sob essa perspectiva, justifica-se o trabalho customizado, bem como os suportes necessários para a sua implantação, como instrutores laborais, plano de transição, adequações de materiais, acessibilidade, entre outros.

Na pesquisa aqui apresentada, os treinandos alcançaram os objetivos propostos, pois foram disponibilizados sistemas de suporte, no caso, a mediação dos instrutores laborais, como explicitado pela Associação Americana de Deficiência Intelectual e Desenvolvimento (AAIDD, 2012). Para além dos dados formais 
coletados, ficou claro a grande vontade dos treinandos em trabalhar e construir uma perspectiva de futuro para sim ultrapassando os limites existenciais até então que lhes foram colocados. Também vale ressaltar uma visível mudança na atitude dos professores e funcionários técnico-administrativos da Faculdade de Educação, que antes consideravam a atuação dos sujeitos com deficiência intelectual como, no melhor dos casos, uma "experiência acadêmica", passaram a considerá-los parte do cotidiano e da equipe produtiva da instituição.

Por se tratar de um projeto de pesquisa, o objetivo era bem delimitado, com foco na avaliação do modelo de trabalho customizado para capacitação de jovens com deficiência intelectual em atividades laborais. Em termos de sua inclusão social propriamente dita, deveria seguir-se todo um processo de inserção desses sujeitos, após o término do seu estágio, no mercado de trabalho formal, oferecendo-se as estratégias e suportes necessários.

Fica como desafio a divulgação a conscientização da importância e os benefícios da customização do trabalho, sua implementação em empresas e outras instituições, bem como a luta para uma maior flexibilização da legislação trabalhista brasileira de forma a facilitar a absorção, no mercado de trabalho, desta população. 


\section{Inclusion of people with intellectual disabilities in laboral activities: $a$ work customization program}

\section{Abstract}

The article discusses, within the scope of Special Education, the professional inclusion of people with intellectual disability, based on the analysis of Brazilian legislation referring to training and insertion of these subjects in work. It presents data obtained in a research that analyzed the implementation of a specialized program, based on the "customized work" model with four young students of professional courses of a specialized school who were interns at the School of Education of UERJ. This concept is based on the training process of the future worker as well as on the creation and/or adaptation of work posts in companies and other institutions, adjusting the employers'demands with the subjects'disabilities. The methodology used was the action-research, involving the field evaluation, training and monitoring the subjects in their work activities. The obtained data show that the customization of the work allowed good performance and production from the trainees, contributing for their social inclusion in their work environment, decreasing the attitude barriers and prejudice. It opens, therefore, a fertile field of actions of Special Education services.

Keywords: Special education. Training and work inclusion. Intellectual disability. Work customization. Professionalization of people with disabilities.

\section{Programa educativo especializado para capacitación e inclusión en el trabajo de personas con discapacidad intelectual}

\section{Resumen}

El artículo analiza en el contexto de la educación especial, la inclusión laboral de personas con discapacidad intelectual, a partir del análisis de la legislación brasileña sobre la educación, la formación y la integración de estos sujetos en el trabajo. Presenta datos de una encuesta que analizó la implementación de un programa especializado con base en el modelo de "trabajo personalizado", con cuatro jóvenes estudiantes de cursos profesionales de una escuela especial que hicieron prácticas en la Facultad de Educación de la UERJ. Este concepto se basa en el proceso de preparación tanto del futuro trabajador como en la creación y/o adaptación de puestos de trabajo en empresas y otras instituciones, adecuando la demanda del empleador con las habilidades de la persona con discapacidad. La metodología utilizada fue la investigaciónacción, que implica la evaluación de la formación práctica y el seguimiento de los sujetos en sus actividades de trabajo. Los datos obtenidos muestran que la personalización del trabajo permitió un buen rendimiento y producción profesional de los sujetos que recibieron el entrenamiento, contribuyendo a su inclusión social en el lugar de trabajo, reduciendo las barreras actitudinales y los prejuicios. Abre, por lo tanto, un campo fértil de actuación de la Educación Especial.

Palabras clave: Educación especial. La formación y la inclusión en el lugar de trabajo. Discapacidad intelectual. Profesionalización de las personas con discapacidad. 


\section{References}

\section{AMERICAN ASSOCIATION ON INTELLECTUAL AND}

DEVELOPMENTAL DISABILITIES - AAIDD. User's guide to accompany the 11th edition of Intellectual disability: definition, classification, and systems of supports. Washington, DC, 2012.

ABREU-ELLIS, C.; ELLIS, J. B. A transição da escola para o trabalho de pessoas com deficiências. In: PLETSCH, M. D.; DAMASCENO, A. (Orgs.). Educação especial e inclusão escolar: reflexões sobre o fazer pedagógico. Seropédica: Editora da UFFRJ, 2011. p. 83-96.

ALMEIDA, L. A. D.; CARVALHO-FREITAS, M. N.; MARQUES, A. L. Análise comparativa das percepções das pessoas com deficiência em relação à inserção no mercado formal de trabalho. In: CARVALHO-FREITAS, M. N.; MARQUES, A. L. (Orgs.). O trabalho e as pessoas com deficiência: pesquisas, práticas e instrumentos de diagnóstico. Curitiba: Juruá, 2009. p. 55-70.

ARAUJO, J. P.; SCHMIDT, A. A inclusão de pessoas com necessidades educacionais especiais no trabalho: a visão de empresas e de instituições educacionais especiais na cidade de Curitiba. Revista Brasileira de Educação Especial, v. 12, n. 2. p. 241-54. maio-ago.2006. https://doi.org/10.1590/S1413-65382006000200007

BECERRA, M. T. et al. Evaluación de un programa de apoyo laboral para trabajores con discapacidad intelectual em tareas con elevada exigencia cognitiva. Siglo Cero, v. 39. n. 226,p. 63-81, 2008.

BRASIL. Lei No 8.213, de 24 de julho de 1991. Dispõe sobre os Planos de Benefícios da Previdência Social e dá outras providências. Diário Oficial da União, 25 jul. 1991.

. Lei $\mathrm{N}^{\mathrm{o}} 12.513$, de 26 de outubro de 2011. Institui o Programa Nacional de Acesso ao Ensino Técnico e Emprego (Pronatec); altera as Leis no 7.998, de 11 de janeiro de 1990, que regula o Programa do Seguro-Desemprego, o Abono Salarial e institui o Fundo de Amparo ao Trabalhador (FAT), no 8.212, de 24 de julho de 1991, que dispõe sobre a organização da Seguridade Social e institui Plano de Custeio, no 10.260, de 12 de julho de 2001, que dispõe sobre o Fundo de Financiamento ao Estudante do Ensino Superior, e no 11.129, de 30 de junho de 2005, que institui o Programa Nacional de Inclusão de Jovens (ProJovem); e dá outras providências. Diário Oficial da União, 27 out. 2011. 
BRASIL. Lei No 13.146, de 6 de julho de 2015. Institui a Lei Brasileira de Inclusão da Pessoa com Deficiência (Estatuto da Pessoa com Deficiência). Diário Oficial da União, 7 jul. 2015.

. Ministério da Educação e Cultura. Conselho Nacional de Educação. Resolução $\mathrm{N}^{\mathrm{o}}$ 2, de 11 de setembro de 2001. Institui diretrizes nacionais para a educação especial na educação básica. Diário Oficial da União, 14 set. 2001.

CEZAR, K. R. Pessoas com deficiência intelectual: inclusão trabalhista: lei de cotas. São Paulo: LTr, 2012.

COELHO, V. P.; ORNELAS, J. Os contributos do emprego apoiado para a integração das pessoas com doença mental. Análise Psicológica, v. 28, n. 3 , p. $465-478,2010$.

COMIN, B. C.; LINCOLN, L. E. S. C. A pessoa com Síndrome de Down e o mercado de trabalho. In: COSTA, M. P. R. A pessoa com deficiência no mercado de trabalho. São Carlos: Pedro, João Editores, 2012. p. 59-78.

CORDEIRO, D. R. C. L. A inclusão de pessoas com deficiência na rede regular de educação profissional. 2013. 184 f. Dissertação (Mestrado em Educação) Universidade Estadual Paulista "Julio de Mesquita Filho", Marília, 2013.

CORDEIRO, D. R. C. L.; OLIVEIRA, A. A. S. A educação profissional de pessoas com deficiência: um levantamento de teses e dissertações. In: CONGRESSO BRASILEIRO MULTIDISCIPLINAR DE EDUCAÇÃO ESPECIAL, 6.; ENCONTRO DA ASSOCIAÇÃO BRASILEIRA DE PESQUISADORES EM EDUCAÇÃO ESPECIAL, 7., 2011, Londrina. Anais... Londrina: UEL, 2011. p. 2662-73.

FOGLI, B. F. C. S. A dialética da inclusão em educação: uma possibilidade em um cenário de contradições: um estudo de caso sobre a implementação da política de inclusão para alunos com deficiência na rede de ensino FAETEC. 2010. 173 f. Tese (Doutorado em Educação) - Universidade Estadual do Rio de Janeiro, Rio de Janeiro,. 2010.

GALER, D. Disabled capitalists: exploring the intersections of disability and identify formation in the world of work. Disability Studies Quarterly, v. 32, n. 3, p. 1-17, 2012.

GILLIES, J. University Graduates with a disability: thet transition to the workforce. Disability Studies Quarterly, v. 32, n. 3, p. 1-18, 2012. 
GIORDANO, B. W. (D)eficiência e trabalho: analisando suas representações. São Paulo: Annablume: Fapesp, 2000.

GLAT, R.; PLETSCH, M. D. Inclusão escolar de alunos com necessidades especiais. Rio de Janeiro: EdUERJ, 2012.

GRIFFIN, C.; HAMMIS, D.; GEARY, T. Introduction to customized job development. In: (Orgs.). The job developer's handbook: practical tactics for customized employment. 3. ed. Baltimore: Paul H. Brookes, 2011. p. 1-22.

JESUS, D. M. O que nos impulsiona a pensar a pesquisa-ação colaborativo-crítica como possibilidade de instituição de práticas educacionais mais inclusivas? In: BAPTISTA, C. R.; CAIADO, K. R. M.; JESUS, D. M. (Orgs). Educação especial: diálogo e pluralidade. Porto Alegre: Mediação, 2010. p. 139-60.

LUECKING, R. G. The way to work: how to facilitate work experience for youth in transition. Baltimore: Paul H. Brookes, 2009.

. Connecting employers with people who have intellectual disability. Intellectual and Developmental Disabilities, v. 49, n. 4, p. 261-73, 2011. https://doi.org/10.1352/1934-9556-49.4.261

. Emprego customizado: empregando pessoas com necessidades especiais. Workshop na Universidade do Estado do Rio de Janeiro, 2012.

. Seamless transition from school to employment. In: Voice: employment and community participation. Down Syndrome Victoria and Down Syndrome NSW Member's Journal. 2013. Disponível em: <http://www. transcen.org/images/stories/TransCen/ publications/PDFs/rlvoicearticle2013. pdf $>$. Acesso em: 1 jul. 2014.

MARTINS, L. A. R. Pesquisa-ação numa perspectiva inclusiva: reflexões e ações. In: BAPTISTA, C. R.; CAIADO, K. R. M.; JESUS, D. M. (Orgs). Educação especial: diálogo e pluralidade. Porto Alegre: Mediação, 2010. p. 161-70.

MASCARO, C. A. A. Capacitação de pessoas com deficiência intelectual para o trabalho: estudo de caso de um curso de educação profissional.2012. 117 f. Dissertação (Mestrado em Educação) - Universidade do Estado do Rio de Janeiro, Rio de Janeiro, 2012. 
MATOS, N. R. V. de. Emprego apoiado: uma análise psicossocial da inclusão da pessoa com deficiência no mercado de trabalho. 2013. 123 f. Dissertação (Mestrado em Psicologia Social) - Pontífica Universidade Católica de São Paulo, São Paulo, 2013.

MELETTI, S. M. F. O significado do processo de profissionalização para o indivíduo com deficiência mental. Revista Brasileira de Educação Especial, v. 7, n. 1, p. 77-90, 2001.

NUNES SOBRINHO, F. P.; LUCENA, U. F. Customização de um posto de trabalho em uma secretaria de escola: um estudo de caso. In: CONGRESSO BRASILEIRO MULTIDISCIPLINAR DE EDUCAÇÃO ESPECIAL, 6.; ENCONTRO DA ASSOCIAÇÃO BRASILEIRA DE PESQUISADORES EM EDUCAÇÃO ESPECIAL, 7., 2011, Londrina. Anais... Londrina: UEL, 2011. p. 2707-17.

OLIVEIRA, M. A.; GOULART JÚNIOR, E.; FERNANDES, J. M. Pessoas com deficiência no mercado de trabalho: considerações sobre políticas públicas nos Estados Unidos, União Européia e Brasil. Revista Brasileira de Educação Especial, v. 5, n. 2, p. 219-32, maio/ago. 2009.

OMOTE, S. Diversidade, Educação e sociedade inclusiva. In: OLIVEIRA, A. A. S.; OMOTE, S.; GIROTO, C. R. M. (Orgs.). Inclusão escolar: as contribuições da educação especial. São Paulo: Cultura Acadêmica, 2008. p. 15-32.

. Inclusão escolar e social: a ética entre o estigma e a inclusão. In: MARTINS, L. A. R.; PIRES, G. N. L.; PIRES, J. (Orgs.). Inclusão escolar e social: novos contextos, novos aportes. Natal: EDUFRN, 2012. p. 39-54.

PETERSON, P. J. Inclusão nos Estados Unidos: filosofia, implementação e capacitação de professores. Revista Brasileira de Educação Especial, v. 12, n. 1, p. 3-10. jan./abr. 2006.

REDIG, A. G. Aplicação e análise de um programa customizado para a inclusão de jovens com deficiência intelectual em atividades laborais. 2014. 197 f. Tese (Doutorado em Educação) - Universidade do Estado do Rio de Janeiro, Rio de Janeiro, 2014.

REDIG, A. G.; MASCARO, C. A. A. C.; CARLOU, A. Inclusão no trabalho de pessoas com necessidades educacionais especiais. In: GLAT, R.; PLETSCH, M. D. (Orgs.). Estratégias educacionais diferenciadas para alunos com necessidades especiais. Rio de Janeiro: EdUERJ, 2013. p. 157-74. 
SANTOS, A. C.; GOMIDE NETO, U.; REZENDE, E. O. Profissionalização da pessoa com deficiência: aspectos históricos. In: COSTA, M. P. R. A pessoa com deficiência no mercado de trabalho. São Carlos: Pedro \& João Editores, 2012. p. 9-22.

SAWAIA, B. B. Uma análise da violência pela filosofia da alegria: paradoxo, alienação ou otimismo ontológico crítico? In: SOUZA, L.; TRINDADE, Z. A. (Orgs.). Violência e exclusão: convivendo com paradoxos. São Paulo: Casa do Psicólogo, 2004. p. 21-42.

SILVA, A. Profissionalização e mercado de trabalho para pessoas com deficiência mental no Brasil: o embuste neoliberal. Inter-Ação, v. 31, n. 2 , p. 231-59. jul./dez. 2006.

THIOLLENT, M. Metodologia da pesquisa-ação. 18. ed. São Paulo: Cortez, 2011.

WALTER, C. C. F. Avaliação de um programa de comunicação alternativa e ampliada para mães de adolescentes com autismo. 2006. $110 \mathrm{f}$. Tese (Doutorado em Educação Especial) - Universidade Federal de São Carlos, São Carlos, 2006.

\section{Informações das autoras}

Annie Gomes Redig: Professora Adjunta da Faculdade de Educação da Universidade do Estado do Rio de Janeiro (UERJ). Vice-coordenadora do grupo de pesquisa "Inclusão Escolar de Alunos com Necessidades Educacionais Especiais no Ensino Regular: Práticas Pedagógicas e Cultura Escolar”. Contato: annieredig@yahoo.com.br

Rosana Glat: Professora Associada da Faculdade de Educação da Universidade do Estado do Rio de Janeiro (UERJ). Diretora da Faculdade de Educação da UERJ, professora do Programa de Pós-Graduação em Educação (PROPed / UERJ), coordenadora do grupo de pesquisa "Inclusão Escolar de Alunos com Necessidades Educacionais Especiais no Ensino Regular: Práticas Pedagógicas e Cultura Escolar” e pesquisadora 1d do CNPQ. Contato: rosanaglat@gmail.com 